\title{
An identification of Critical Success Factors (CSFs) on user perspectives in diffusing e-Information Service in the University of Colombo Library
}

\author{
Chaminda Chiran Jayasundara \\ Senior Assistant Librarian (E-Learning) \\ University of Colombo \\ Colombo 07 \\ Sri Lanka \\ Tel: +94112586432 \\ Fax: +94 112583043 \\ Email: chaminda@lib.cmb.ac.Ik
}

\begin{abstract}
Access to fresh international research is a prerequisite for meaningful research endeavor. With the objective of providing online scholarly information, the e-Information service was established in 2003 and it was quickly became the hart of the library services and a catalyst for change and collaboration. The e-Information service of the University of Colombo's leading edge resource based teaching and learning facility, provides a collaborative interdisciplinary environment where campus wide access is granted. Identification of CSFs and degree of user satisfaction towards the e-Information service were the objectives of this study. The method of collecting data was informal discussions with 10 postgraduate students, 05 undergraduate students and 8 lecturers who were familiar with using e-resources and where comfortable using IT in FGS, Education, Arts and Science faculties. Physical observations in e-Resource centers were also made. The data collection was preliminary focused on four key areas namely Infrastructure, Support, Resources and Patrons. Conducting e-Information Literacy Development Programmes, enhancing resource sharing activities, strengthening einformation acquisition and delivery procedures were important suggestions.
\end{abstract}

\section{Introduction}

\section{Profile of the university}

The history of higher education in Sri Lanka is closely linked to the University of Colombo. The University of Ceylon was established in 1942 and toady, the University of Colombo has a great advantage over the other institutions in the higher education sector on account of its unique location and academic excellence. It is a metropolitan university and the students are at a distinct advantage of being at the hub of the cultural, economic and political activity in the country.

At present, University of Colombo is the second largest university in Sri Lanka with a student population of about 7160 . The profile of the University of Colombo is presented in the table I which elucidates the basic components of the university student population, academic staff and the details of the library system. 
Table I: Profile of the University

\begin{tabular}{||ll|}
\hline \hline Name and Location & University of Colombo, Sri Lanka \\
Number of Students & 7160 \\
Number of Teaching Staff & 412 \\
Library Staff & \\
1. Professionals & 11 \\
2. Paraprofessionals & 37 \\
3. Supporting & 17 \\
4. Minor Staff & 20 \\
Professional Staff/Student ratio $\quad 1: 651$ \\
Collection \\
1. Central Library & 211,000 \\
2. Science Library & 27,000 \\
3. Medical Library & 48,000 \\
Periodicals & \\
1. Central Library & 469 \\
2. Science Library & 83 \\
3. Medical Library & 300 \\
Reading Room facilities & \\
1. Central Library & 565 seats \\
2. Science Library & 150 seats \\
3. Medical Library & 150 seats
\end{tabular}

\section{The University Library}

The University of Colombo library system consists of the Central Library and two faculty libraries namely Science Library and Medical Library. The Central Library is situated in a five storied building which contains books, periodicals and electronic information resources in Humanities, Education, Law, Management, and Social Sciences. The Law library collection occupies the whole of second floor of the Central Library. Text books, Periodicals, Law reports etc. are included in the collection. All the library materials in this collection are treated as reference materials and only law students are allowed to borrow textbooks for over night and weekend reading. The library of the Medical College was founded in 1870, the same year that the medical faculty was inaugurated. The library is the second oldest medical library in Asia. The medical library is the focal point of the Health Literature Libraries and Information Services Network (HELLIS) and privileged as the WHO depository library in the country. Both Medical Library and the Science Library consist of Permanent Reference section, Reference section, Reading room, Lending section, Periodicals section and the Computer room. The library also adds 5000 to 6000 materials to its stock every year. The central library has also received depository status 
recently from the International Monetary Fund (IMF) for its publications and communications.

\section{Statement of the objectives}

The research has been undertaken to urge the policy makers to support proper investigation, planning and implementation of the e-Information service at the University of Colombo in effective manner. This would be the first study of this nature in Sri Lanka. Main objectives of the study were,

1. To investigate the existing system of the e-information service

2. To identify the Critical Success Factors which are crucial to the success of the service

3. To make recommendations based on the findings for decision/policy makers in the university system

\section{Significance of this study}

This study makes an important contribution to the literature on e-information service as research in this area is still in its infancy in Sri Lanka. The current lack of research also increases the likelihood that e-information service initiatives are based on ad hoc practice, and thus are constrained from achieving their full potential. This paper provides relevant findings for library and information professionals, managers, programme cocoordinators, and seek to assist decision-making related to the implementation and management of electronic services.

\section{Research Methodology}

The method of collecting data was in two routines such as physical system observation and informal discussions with 10 postgraduate students, 05 final year undergraduate students and 8 lecturers who were familiar with using the e-resources and comfortable in using Information Technology. The method of selection was purely based on purposive sampling as the researcher wanted to recruit the subjects thoroughly based on their usage on e-resources. They were selected form Faculties of Graduate Studies, Education, Arts, Law and Science. The formation of the sample was two lecturers and two postgraduate students from the Faculty of Graduate Studies, Two lecturers, one undergraduate and three postgraduate students form the Faculty of Education, Two lecturers, one undergraduate and three postgraduate students from the Faculty of Arts one lecturer, one undergraduate and one postgraduate students form the Faculty of Law and one lecturer, two undergraduate and one postgraduate students from the Faculty of Science. Physical observation of e-Resource centers located in main and science libraries of the university were also made by the researcher himself. The data collection was specially focused on four key areas namely Infrastructure, Support, Resources and Patrons. An instrument for specifying the Critical Success Factors within each category was developed in accordance with the identified group of 
determinants/Critical Success Factors (CSFs) i.e. Infrastructure, Support, Resources and Patrons. Each CSF category was observed via a group indicators and the selection of indicative CSFs were drawn from the prevailing literature, personal experience and informal discussions with the genuine users in the service.

\section{Discussion}

\section{e-Information Service}

The impact of student-centered teaching methods such as Problem-Based Learning (PBL), Evidence-Based Learning (EBL), Reflective Study and group work had resulted in a growing need for more flexible learning spaces. The increasing number of computer usage for learning, teaching, research and communication responsibilities has lead to significant changes in user characteristics including, their needs and expectations. The main purpose of modern information services based on electronic resources in the library system is to provide an integrated learning environment where the patrons have access to electronic learning using available e-information resources and appropriate support structures.

According to the opinions of the researchers, access to fresh international research results as they are presented in international scholarly journals, is a prerequisite for meaningful research endeavor. With the objective of providing online scholarly information, the e-information service was established in 2003 at the university of Colombo library and it very quickly became the heart of the library services and a catalyst for change and collaboration. The e-Information service of the University of Colombo's leading edge resource based learning and resource based teaching facility, provides a collaborative interdisciplinary environment with over 60 personal computer workstations in three laboratories in the Main, Science and Medical libraries which facilitates e-accessing.

\section{Infrastructure}

e-Information service provides infrastructure for functional integration of the information and the technology services, information literacy, learning support offered by the University of Colombo library. The formal instructing space that is the seminar room is well positioned in the library building to conduct training programmes on information literacy and skills development. It has a direct access point, comfortable seating, editing room facilities including recording and reprographic and good lighting and sound system which is very particular to the room. The seminar room is fitted with a removable study carols networked PCs for greater flexibility and can seat 150 users a given time. The room is equipped with state-of-the-art audiovisual and presentation technology. The Library staff of the University of Colombo consists of senior level Librarians with a sound knowledge of ICT and electronic resources which are particularly needed for teaching, learning and research process of the university. In addition one Senior Assistant Librarian is in charge of this division with one Computer Application Assistants and a few number of well trained Library Assistants in the field of ICT and e-Resources. As such the work load in relation to e-resources is distributed among the library staff. Therefore no extra expenses for manpower are incurred. 
The Information Technology infrastructure in the university library has been designed to provide maximum flexibility to adapt to changing teaching and learning technology requirements. The buildings dedicated for library functions are fully wired to each study space, allowing the provision of desktop computers as well as the use of user-owned laptops. The e-Resource Centre located in the central Library consists of 20 personal computers with net connectivity and another resource centre is positioned in the Science Library with 14 computers for user access.

\section{Support}

SIDA Research cooperation with Sri Lanka; Library Support to University Libraries in Sri Lanka programme of the University of Colombo has so far provided Sri Lankan university libraries with scientific journals. The support has now been taken a new turn towards subscription to online databases. Activities are carried out in collaboration with the United Kingdom based organization called the International Network for the Availability of Scientific Publications (INASP). SIDA's support can be seen as assistance to the provision of access to important scientific and research electronic information sources, and opportunity to make research done in Sri Lanka available to the world.

Library support from SIDA is to improve access to e-information for all higher educational institutions in Sri Lanka and also to launch "Sri Lanka Journal Online (SLJOL)" a project to disseminate research done in Sri Lanka. INASP negotiates countrywide licenses for each subscription year for full text e-information with access to over 5000 full text on-line journals in Science, Technology, Medicine, Social Sciences and Humanities. The beneficiaries from this endeavor are not only the academics from universities, but also users of the other higher educational institutions, research institutions and non-profit making institutions. INASP negotiates discounted rates from the online database producers for countrywide licenses, conduct training workshops, and provide guidance and support to design.

\section{The System}

The library has build up two way information dissemination portal based on a routine of electronic information provision: "Library Intranet" and "Library Access via Net".

The Intranet of the library provides valuable data on information resources and authenticated e-resources particularly important for its patrons and software which are exhaustively important to the consumers to smoothly carry out their resource based learning tasks. Outsiders are forbidden to access the Intranet premises. Especially the link for "Downloads" of which the purpose of desktop software is to meet the general student computing needs for accessing, downloading, reprocessing of information for their teaching, learning and research activities. In addition to the traditional printed resources available in the university of Colombo library, the library now offers many electronic resources published by prestigious publishers such as EBSCO Host, Blackwell's, Emerald etc., and most of which are available online to all researchers and academicians via the e-Access Gateway located in the library webpage which is the 
"Library Internet Portal". SIDA/SAREC library support programmme has thus far provided funds for country wide access to some of the databases while Ford Foundation, Williams S. Hein and Company has granted some funds for JSTOR and Hein Online respectively. The university also provides some treasury funds for the Emerald.

The e-Access Gateway is the electronic portal based on the net which facilitates the users to retrieve information from the library databases, e-journals and outside subject gateways through the library webpage. The Library does not charge form the staff and students for accessing to electronic resources, including web-based licensed databases, electronic journals, and some selected Internet resources. The e-Resources available in the library can be grouped into three main categories.

1. Subscribed electronic databases

2. Open Access electronic databases

3. Trial Access electronic databases

Subscribed electronic journals have been divided into two parts such as password authenticated databases and IP authenticated databases. Password authenticated databases are Blackwell's Synergy, EBSCO Host, Emerald, CABl'S Global Health Online databases. IP authenticated databases are American Society of Agricultural and biological Engineers (ASABE), American Society of Civil Engineers, Beech Tree Publication, University of California Press, Palgrave McMillan Journals, SAGE Publications, National Academy Press, Hein Online, H.W. Wilson Database, JSTOR and Commonwealth Universities Database Online Service. Open Access electronic databases are DOAJ-Directory of Open Access Journals, INASP Free Resources, American Chemical Society, American Society Journals, MIT Open Courseware materials and SciELO. Trial Access databases are Science Direct and Bentham Science Journals

\section{Service}

The library provides a consultation service by launching instructional sessions in the library and in the faculties in collaboration with the academic staff members concerned. This service includes assistance for teachers/students on using public workstations in the e-Resource centers, instructing how to use particular databases and assisting the patrons on a point of need basis. Specifically it provides a Help Desk for immediate queries in the centre with staff working on shift basis. The Library Assistants at the Help Desk have a general knowledge of electronic resources, software and databases in the university library, on the Internet, and on the campus network. They support the users on how to use the major electronic resources available in the library, including WWW resources, and on-line databases. In addition they provide general computer skills support, scanning, downloading and assisting patrons in the use of e-Resource centre in the library system. However there is no dedicated Reference Librarian based at the Help Desk but the Senior Asst. Librarian in-charge of e-Learning activities instructs the users extensively to derive the maximum benefits of information skills programmes conducted by his department. 


\section{Critical Success Factors (CSFs)}

Critical Success Factors (CSFs) in relation to the e-information service can be grouped into four categories. i.e. Infrastructure, Support, Resources and Patrons. University students and teachers are becoming more diverse and demand for e-learning based courses is increasing (Papp, 2000 and Volery and Lord, 2000). Students need to have time management, discipline and computer skills in order to be successful in the elearning area. The expansion of Information technological gear resulted in changes in modern education. E-learning integration into university courses is a result of the IT explosion. As a result, IT is the engine that drives the e-learning based components of a course of critical importance to the success and student acceptance of e-learning. Consequently, ensuring that the university IT infrastructure is rich enough to address the needs, reliable and capable of providing the courses with necessary tools is critical to the success of e-learning. According to the results of the research, it has identified a number of CSFs in relation to the broad areas refered to earlier.

\section{Infrastructure}

Understanding the implications of technical infrastructure on the application of eLearning media is essential to a successful strategy.

1. Easiness of accessing the Internet - The wide availability of Internet access of the university is an advantage to the service. The e-Information service is using that fact to promote service growth in the library in line with the dissemination of electronic information.

2. Network Bandwidth - The other important aspect of internet speed. Using high Internet bandwidth, this would be better thought of as the speed limit on the information flow. It is observed as the sluggishness between the user clicking on a link and the page starting to download. However, in early days the accessibility to Internet was incredibly time-consuming, but the bandwidth has now been upgraded by the University for prompt access. It was really critical to the success of high usage of the e-Information service.

3. Availability of PCs with internet connectivity: This is also very critical as the student now have adequate number of computers in the library and their own departments to access the resources directly.

4. Learner focused technology: The library must find optimum balance of training tools while incorporating online learning within the user training programme. The patrons emphasized individually and learner focused training method in order to emphasize continued training and learning on e-resources which has so far contributed to improve their performance in their particular academic disciplines.

5. Availability of computer labs with LEARN connection: Although the teachers and the postgraduate students of the university have an adequate amount of computing facilities at their workplace and at home, undergraduate students do not have access to facilities in this emerging domain. Nevertheless they are now 
fairly satisfied with the expansion of computer laboratory systems in the university including the library in which the students are able to get direct access to the electronic information resources satisfactorily.

\section{Support}

6. Technical support for immediate queries from the library : Continuous technical support was offered via the library web page and, Intranet, and Help Desk. This was an efficient way to provide support to many academics and students in the university to improve the better access to relevant resources properly in a very short time. The users emphasized that although the ongoing individual support is not adequately encouraged, all individual questions were answered promptly. Those trained by the central library, were expected to support other people in their departments.

7. e-Information skills development programmes : The relative advantage attribute of the e-Literacy programmes, emerged as the most important of the Critical Success Factors associated with the characteristic of the e-Literacy. Although some people especially academic staff members identified the low IT skills as a barrier for adoption, and therefore a degree of complexity in the new technology, in the long run they managed to overcome this difficulty. Some academic members have recognized that the low information skills as a barrier to access particular information resources. On the other hand, the postgraduates and some academic staff members had very high IT skills but did not see a clear advantage in adopting the service properly. The e-Information skills development programmes conducted by the library are very critical in accessing relevant resources for their teaching, learning and research activities within the university and outside the university.

8 e-Mail alerting service from the library : As the library brings up to date the academic staff members of the university in line with the new acquisition of modern electronic resources, it was really useful for the teachers for accessing wide assortment of information which they required for professional competency. However, this has not been thoroughly emphasized by the students because of the lack of proper system to educate the students in relation to the new acquisition of e-resources.

9. Informal contracts and leadership strategy: Interpersonal communication channels were most effective in the university library. Frequent informal contacts between library staff and the users were worthwhile in motivating the patrons to be used online information resources. However, further examination of the possibilities provided by this mode of analysis is still needed for the final review.

10. Establishment of mutual trust between users and staff: Establishing a stable work model can allow staff and users to be able to trust each other. As this trust has already been effectively established, teams working as a part of a broader knowledge community can work together more effectively in the university system. The patronage given by the Librarian and the Senior Assistant Librarian 
in-charge of the section were highly admired by the academic staff members of the university.

11. Provide learning time and space : A number of users from the faculty of Science stressed that they do not have adequate time for learning and no proper space is available in the Science Library. Therefore they used to come to the main library and then the support from the main library is absolutely unpleasant for the reason that they are not allowed to use the computers located in the main library. However one of the major advantage of this service mentioned especially by academic staff members in all faculties was that the users can enjoy the flexibility of learning anytime and anywhere. They emphasized that the databases based on usernames and password accessibility are extremely helpful because of the easy access even at their home and cyber cafes. However, low response in this regard was received from the student users for the reason that they do not have wide spread of accessible media at their own place and lack of money for cyber cafe expenditures.

\section{Resources}

The users of the service thoroughly emphasized that the salient features of the databases were very critical in accessing the specific information. They particularly emphasized that Emerald, Blackwell, EBSCO Host, Science Direct and JSTOR have very prominent characteristics over the other databases which are subscribed and granted free access. Because of these trendy and popular features, the users were compelled to make use of the service to acquire relevant information for their teaching and learning work. The factors they basically identified were

12. Encouragement of retrieving more information than the traditional methods

13. Easiness to download resources

14. Accessing wide range of materials than might otherwise be available through local library

15. Value added features

16. Convenience access

17. Approachability of up-to-date information.

\section{Patrons}

18. Previous experience in IT: Users' support for e-information service is critical to its overall success. It is essential that the users understand their roles and able to use various e-resources in diverse media competently. Their previous experience in IT and user feedback greatly influenced the success of the e-information service strategy.

19. Information Literacy (e-Literacy): Knowledge on e-Literacy skills is also very critical and those who are very competent with e-information skills were very successful in accessing the resources.

20. Degree of satisfaction: This was very critical according to the all users of the service. 
In sum up, integral to the success of e-Information service is an integrated support service, e-information skills development which are proactive, clear and intuitive to the library patrons.. Several areas of improvement have been identified and the proactive ongoing development of this service is based on purpose and role, not structure, with end user feedback and needs guiding the service levels. The driving principle in evolving the e-Information service philosophy is to integrate the physical learning environment, the virtual learning environment and e-Information literacy development.

\section{Barriers to success}

Although low IT skill levels may be a barrier for proper adoption of the service, if the problem is identified, it can be overcome and the users can become successful adopters.

Lack of information literacy skills is a barrier to accessing information, but here access is considered only from two aspects; on campus and off campus. Students cannot use the library nor appreciate the available services unless they are aware of what is offered although the University already offered a general orientation to all students. Additionally, the e-information service, in conjunction with the faculty members and particular learning support services, should initiate e-information service orientation for under graduate and graduate students to well equip the patrons in modern areas of electronic resources and uses. The university library website has to be redesigned for easier navigation and links to a range of resources and services were particularly emphasized by the users.

The analysis of the problems experienced in the e-information service, major emphasis could be placed on poor information flows including insufficient feedback from the departments and the absence of regular links with particular departments in the university. Lack of time was suggested by the majority of academic staff members and some of the postgraduate students as a barrier to use electronic information resources.

\section{Conclusion}

The CSFs can be observed as a few variables and also regarded as some key areas of business operations. The decisions and efforts of executives in the university library sector to deal with these Critical Success Factors will affect the performance of business operations and its sustainable competitive advantage. The adoption of e-learning technology is a complicated process of establishing and developing an integrated information technology system. This paper in line with the literature, specified Critical Success Factors (CSFs) which can assist university library to efficiently and effectively adopt e-learning technologies. All indicators of the attitudes of the users and controllers indicate high level of criticality to the success. And also user motivation, information and IT competency, previous experience with the e-information resources were very important factors which also contribute to the success of the service. Therefore, from the 
promotion of a knowledge community based e-learning, this investigation can probe the development of key factors to success in promoting a working method of knowledge management for business as well as providing a few suggestions and debates.

\section{Recommendations}

Improving the general information and IT skill level of academic staff and the students: The University library had a very successful series of e-Resource Training programs. Since 2003, over 1500 staff and postgraduate and undergraduate students attended these courses. However, as some of the people in this research project found, some academics have very limited IT skills limited to basic use of word processing and electronic mail. They have no capability in searching internet and electronic information resources.

According to some of the people interviewed, many academics prefer learning new IT skills combined with e-information at their desk, rather than attending traditional and additional courses. To try and address this problem, the University can provide a basic training package based on specific software and then they can take these programs home and run them on their own computers as well.

Electronic discussion group: A similar facility to electronic discussion group or online support system preferably chat system would be useful in this University to allow students and academic staff members adopting discussing their local problems and helping each other providing insights from their own experience. Such a facility could ease the load of the central e-Information service group of the library. They could respond to those questions that have not been answered by other library professionals and caretakers. It can also eliminate duplication so that each question has to be addressed only once and all other users can benefit from the answer.

It is clear that the student-centered resources, facilities and attractive spaces in the University of Colombo Library have greatly improved user life in using electronic resources effectively. The integrated service model implemented in the university of Colombo library has been successful and it meets the needs and expectations of its

patrons. Several areas for improvement have been identified and the proactive ongoing development of this service is based on purpose and role, not structure, with end user feedback and needs guiding the service levels properly. The driving principle in growing the e-Information service is to continually look for opportunities to integrate the physical learning environment, the virtual learning environment and learning supporting an efficient and effective manner.

\section{References}

Beagle, D. (1999). "Conceptualizing the Information Commons", The Journal of Academic Librarianship, 25(2), 82-89.

Crockett, C., McDaniel, S., Remy, M. (2002). "Integrating Services in the Information 
Commons", Library Administration \& Management, 16(4), 181-186

Papp, R (2000). Critical Success Factors for distance learning. Paper presented at the Americas Conference on Information Systems, Long Beach, CA, USA

Volery, T and Lord, D. (2000). Critical Success Factors on online education. The International Journal of Educational Management. 14(5), 216-223

Duval, E. (2005). A Learning Object Manifesto.

http://www.cs.kuleuven.ac.be/ hmdb/ProlearnIClass/papers/Duval.pdf (Accessed on 10 May 2007)

Duval, E. \& Hodgins, W. (2004). Making metadata go away: "Hiding everything but the benefits".http://purl.org/metadataresearch/dcconf2004/papers/Paper 15.pdf (Accessed on 10 May 2007)

EduSpecs. (2005). Benefits of Specifications and Standards. from: http://www.eduspecs.ca/pub/specificationsandstandards/benefits of standards.html (Accessed on 10 May 2007) 